Quim. Nova, Vol. 28, No. 6, 1006-1009, 2005

\title{
USE OF THIN FILMS OBTAINED BY PLASMA POLYMERIZATION FOR GRAIN PROTECTION AND GERMINATION ENHANCEMENT
}

\author{
Rodrigo A. M. Carvalho, Alexsander T. Carvalho, Maria Lúcia P. da Silva* e Nicole R. Demarquette \\ Escola Politécnica, Universidade de São Paulo, Av. Prof. Luciano Gualberto, Trav. 3, 05508-900 São Paulo - SP \\ Odílio B. G. Assis \\ Empresa Brasileira de Pesquisa Agropecuária, Rua XV de Novembro, 1452, 13561-160 São Carlos - SP
}

Recebido em 5/10/04; aceito em 2/3/05; publicado na web em 11/7/05

\begin{abstract}
In this work, preliminary results of the use of hydrophobic thin films obtained by plasma deposition to protect grains and seeds are presented: grains coated by the films did not present biological degradation when stored in a saturated water vapor environment, but had their germination accelerated in the presence of water. A model that explains the difference of behavior of the films when exposed to water in vapor form or in liquid form, based on the formation of microchannels within the film that lead to water uptake in seeds, is presented. The model was successfully tested using quartz crystal measurements, which showed that the microchannels within the films can favor the adsorption and permeation of water when the films are immersed in water.
\end{abstract}

Keywords: germination enhancement; plasma polymerization; TEOS.

\section{INTRODUCTION}

Cold plasma processing is an interesting technique that can be used for several applications. Plasma creates extremely reactive species like ions, free radicals and metastable species, which allow reactions to occur at much lower temperatures than when using conventional methods, or even reactions that would not occur at all, if the reagents are not under plasma conditions. Organic silicon compounds together with oxygen $\left(\mathrm{O}_{2}\right)$ are frequently used in plasma deposition to obtain silicon oxide, which is an important dielectric in the microelectronic industry. In particular, plasma deposition of TEOS $+\mathrm{O}_{2}$ presents several advantages such as an easy deposition in several substrates ${ }^{1}$ and low deposition temperatures ${ }^{2}$; the presence of $\mathrm{O}_{2}$ provides excited species ${ }^{3}$ (oxygen atoms or ions) that react with the monomer and remove the carbon from TEOS molecule as shown in Equation 1 below.

$\mathrm{Si}(\mathrm{OEt})_{4}+12 \mathrm{O}_{2} \rightarrow \mathrm{SiO}_{2}+8 \mathrm{CO}_{2}+10 \mathrm{H}_{2} \mathrm{O}$

In general, the quantity of $\mathrm{O}_{2}$ that is admitted to the plasma governs the dielectric properties of the films obtained ${ }^{4,5}$ and depends on the organic silicon compound used for deposition ${ }^{6}$. For TEOS deposition, the removal of carbon radicals is not easy and some contamination will remain even if plasmas with high-energy ion bombardment are used ${ }^{7,8}$, therefore TEOS kinetics is not simple. Although TEOS plasma polymerization has been seldom attempted, Ihara and Kiboku ${ }^{9}$ showed that it is possible to deposit it on alumina. In previous studies, we showed that it was possible to obtain a silicone type structure from TEOS plasma polymerization ${ }^{10}$. The film obtained can be used for the development of humidity sensor and protection against ultraviolet radiation. One of the main characteristics of the film is its fast reaction with water in liquid form but inertia to water vapor ${ }^{11,12}$; the film is hydrophobic, but once immersed in water, it becomes hydrophilic.

Lignocellulosics, i.e. wood, agricultural crops, seeds and residues, such as bagasse or corn stalks, present a fast biological

*e-mail: malu@1si.usp.br degradation because organisms identify specific polysaccharides in the cell-wall and are capable of breaking them down into digestive units. The main site for reactivity in these polymers is attributed to the hydroxyl groups mainly present in cellulose. The hydroxyl groups also define the high affinity towards water ${ }^{13}$. Therefore, several chemical treatments have been developed to enhance hydrophobic features and resistance to biodegradation of woods ${ }^{14}$, and more recently of seeds and crops ${ }^{15,16}$. Such modification has been frequently used to incorporate radicals, especially non-polar functional groups (e.g. $\mathrm{CH}_{3}$ ) which are strongly hydrophobic. In particular, TEOS was already used for that purpose but only to deposit silicon oxide for increasing water repellence ${ }^{17}$. However, the possibility of increasing water uptake might, in some cases, be strategically interesting. In the presence of constant water the cellulose coat of the grains swells, creating ruptures and scarifying the subjacent layers ${ }^{18}$ resulting in an accelerated germination process. Therefore the enhancement of water affinity could have special applications for seeds presenting high dormancy periods since the presence of moisture accelerates coat degradation.

This study is a preliminary investigation of the applicability of TEOS-plasma deposition for treating seeds for protection during storage and increase of water affinity to accelerate germination. The investigation was carried out with organic silicon compound in order to obtain the formation of polymeric structures on bean seeds using TEOS and TEOS $+\mathrm{O}_{2}$ plasma polymerization. TEOS $+\mathrm{O}_{2}$ plasmas enhance $\mathrm{Si}-\mathrm{O}-\mathrm{Si}$ formation at the expense of $\mathrm{SiOH}_{2}$ formation ${ }^{11}$, therefore, a small amount of $\mathrm{O}_{2}\left(\mathrm{TEOS}: \mathrm{O}_{2}\right.$ ratio= $\left.1: 9\right)$ was used although a huge ratio $(1: 100)$ is normally proposed for oxide formation ${ }^{19}$. TEOS $+\mathrm{O}_{2}$ polymerization is expected to result in a more rigid film than TEOS polymerization. The influence of plasma treatment on germination was evaluated in laboratorial conditions.

\section{EXPERIMENTAL PART}

Plasma deposited films were obtained using tetraethoxysilane (TEOS), $\mathrm{Si}\left(\mathrm{OCH}_{3}\right)_{4}\left(\right.$ Merck industrial grade) with or without $\mathrm{O}_{2}$ (White Martins, research grade). The equipment used for plasma 
deposition was a rotating reactor, coupled with a RF power supply operating at a frequency of $13.56 \mathrm{MHz}$ and with a power of $200 \mathrm{~W}$ dissipated to the electrodes. Details of the plasma reactor used in this study were previously reported by Tan et al. ${ }^{20}$.

Two types of plasma deposition were made on different batches of commercial seeds of beans (Phaseolus vulgaris L): TEOS or $\mathrm{TEOS}+\mathrm{O}_{2}$ deposition. Due to the high degassing characteristic of the beans, TEOS deposition had to occur in two steps: a previous treatment of TEOS polymerization, $120 \mathrm{~W}, 1.3$ Torr, $10 \mathrm{~min}$, using a closed chamber mode ${ }^{21}$ followed by TEOS or TEOS $+\mathrm{O}_{2}$ plasma polymerization using the processing conditions reported in Table 1. In order to characterize the deposited films a silicon wafer was maintained in the reactor during the depositions. The deposited films on these silicon wafers were characterized using profilemeter, to determine their thickness, measurements of contact angles formed by drops of water to characterize their hydrophobicity and infrared spectroscopy to determine the main species present in the film. The main results of the film characteristic are shown in Table 1. The thicker film obtained for TEOS deposition is most likely due to a more porous structure, which originates from the high amount of carbon radicals that lead to silicone like structure ${ }^{11}$.

To evaluate the efficiency of the deposited films for bean protection, some simple laboratorial tests were carried out.

1. Qualitative measurements of water contact angles were performed. Due to the non-uniformity of the bean surface, it is not possible to evaluate accurately the contact angle formed by a drop of water at the surface of the bean and the results should only be considered qualitative. However the measurements pointed out a huge difference between treated and not treated beans. The "contact angles" observed at the beans surface increased from $50^{\circ}$ to $80^{\circ}$ after plasma treatment. The same behavior was obtained for both TEOS and TEOS $+\mathrm{O}_{2}$ films.

2. Treated and untreated beans were kept in a dissecator with water for 10 days at $10 \mathrm{mTorr}$ simulating very humid weathering condition during storing.

3. Treated and untreated beans were immersed in water and samples were removed every three minutes to observe their surface visually and by optical microcopy.

4. A germination test was conducted. The germination of the treated seeds was observed over a period of 10 days. Batches of 200 seeds, corresponding to each different plasma treatment were placed on the top of filter paper inside Petri dishes (90$\mathrm{mm}$ diameter). The disks were permanently moistened with distilled water and the seeds allowed to grow at room temperature. Germination counts were made daily and were defined as emergence and extension of the radicule to at least 5 -mm from the seed coat. The seedling count germination percentages were compared to the untreated seed samples.

\section{RESULTS AND DISCUSSION}

Figure 1 shows a typical surface of untreated and TEOS treated beans kept in a dissecator with water for 10 days at 10 mTorr. It can be seen that the untreated beans were attacked by microorganisms whereas none of the treated beans were. The same behavior was obtained for TEOS $+\mathrm{O}_{2}$ film. More than 100 beans were evaluated in several batches. For all the untreated beans the attack by microorganism was observed in a severity ranging from 10 to $50 \%$.

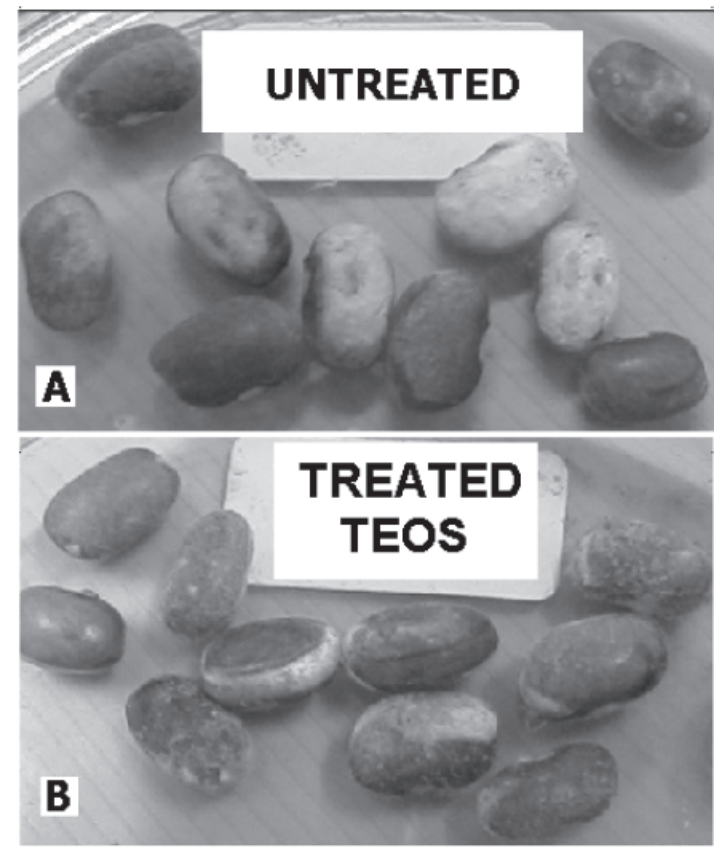

Figure 1. Physical aspect of untreated A) and treated B) grains maintained for 10 days in water saturated vapor environment

Figure 2 shows the physical aspect of the beans after different times of immersion. In this case the beans were treated with TEOS or TEOS $+\mathrm{O}_{2}$ plasma and the behavior was the same.

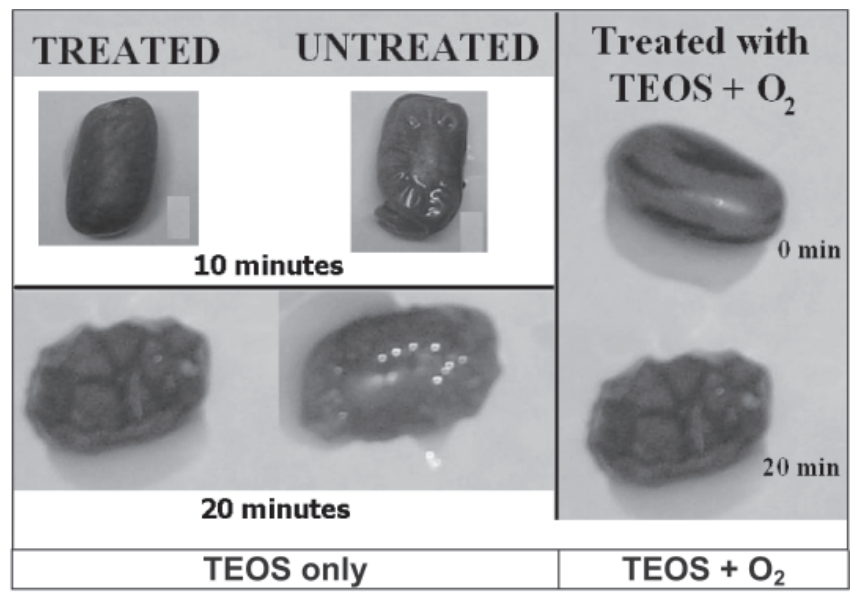

Figure 2. Physical aspect of grains treated and untreated with TEOS only or treated with TEOS $+\mathrm{O}_{2}$ after different times of immersion in water

Table 1. Deposition conditions and thickness, water contact angle measurement and relative intensity of main polar species for the deposited films on silicon wafers. Deposition time is always $5 \mathrm{~min}$

\begin{tabular}{|c|c|c|c|c|c|c|}
\hline \multicolumn{3}{|c|}{ Deposition conditions } & \multirow{2}{*}{$\begin{array}{c}\text { Thickness } \\
(\AA)\end{array}$} & \multirow{2}{*}{$\begin{array}{l}\text { Water contact } \\
\text { angle }\left({ }^{\circ}\right)\end{array}$} & \multicolumn{2}{|c|}{ Relative intensity of main species } \\
\hline Pressure(mTorr) & Power(W) & $\mathrm{O}_{2}:$ TEOSratio & & & $\mathrm{CH}_{\mathrm{n}} / \mathrm{Si}-\mathrm{O}-\mathrm{Si}$ & $\mathrm{OH} / \mathrm{Si}-\mathrm{O}-\mathrm{Si}$ \\
\hline 200 & 200 & 9.1 & 100 & 80 & 0.0538 & 0.0629 \\
\hline 100 & 200 & 9.4 & 100 & 80 & 0.0805 & 0.0536 \\
\hline 200 & 200 & 0 & 1000 & 80 & 0.1775 & 0.0811 \\
\hline
\end{tabular}


It can be seen that untreated beans adsorbs water readily resulting in a change of its surface (wrinkled aspect). In the case of the treated beans the adsorption and penetration of water is delayed but occurs after a time that varies from 10 to $15 \mathrm{~min}$. This qualitative experiment shows that, although the films turn the bean resistant to water vapor, it does not turn it resistant to immersion in water. Similar behavior was obtained with both films studied.

Figure 3 shows the percentage of seeds that have germinated as a function of time for three types of seeds: a) untreated reference seeds; b) treated by TEOS plasma; c) treated by TEOS $+\mathrm{O}_{2}$ plasma. It can be seen that for both types of plasma treatment, the germination of the seeds occurs much faster. In the case of untreated beans, the percentage of seeds that germinated seem to increase linearly with time (after an inhibition time of three days) reaching $60 \%$ after ten days. In the case of plasma treated beans, the germination is much faster: on the third day $80 \%$ of the treated seeds have germinated whereas only $28 \%$ of the untreated seeds have germinated, and much more efficient: after four days around $95 \%$ of the seeds have germinated. The similarity observed between both films could be due to the high degassing of the seeds that enhances for both TEOS and TEOS $+\mathrm{O}_{2}$ plasma the formation of silicon oxide like rigid structures at the beginning of the process.

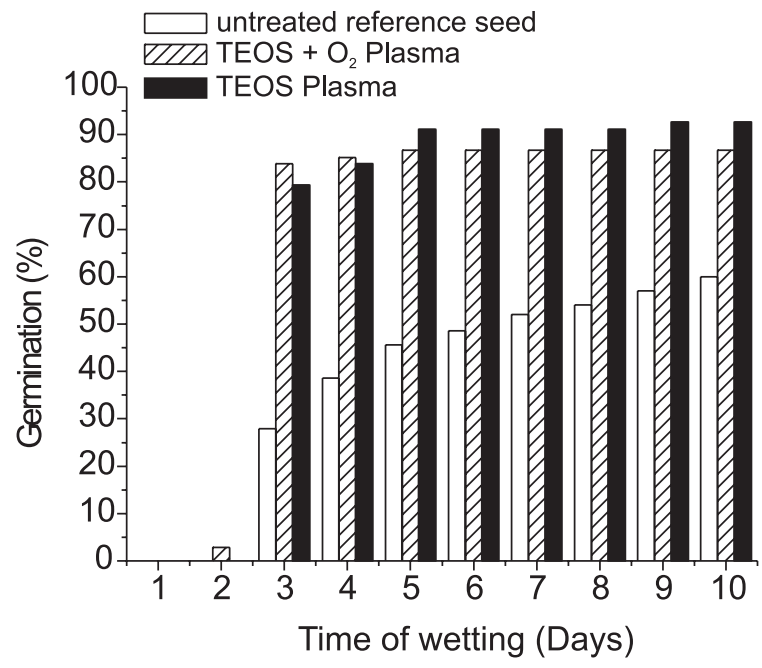

Figure 3. Germination fraction of beans seed as result of TEOS coatings

The faster and more efficient germination process is most likely due to a more efficient water uptake of the plasma-modified seeds. Although, seed development is a complex phenomenon, ruled by several physiological and environmental processes, which depend on the seed type, it is well known that the affinity towards water is an important factor in starting germination in any type of cultivars. According to Taylor ${ }^{22}$, seeds water uptake follows a triphasic well defined pattern: i) an initial rapid uptake phase known as imbibition, then ii) a lag period followed by iii) a second and fundamental increase in water uptake, associated with seedling growth. The hydration in third phase is determinant for germination starting and involves a necessity of a specific quantity of water directly to contact the seed ${ }^{23}$. From the experimental results, it is reasonable to assume that the films deposited at the surface of the seeds enhance the hydration of the seeds and consequently the efficiency of their germination. In order to quantify the water uptake, gravimetric tests were carried out. However, due to the amount of parameters involved, no meaningful results were obtained.

The resistance to humid environment and enhancement of germination of the treated beans may be explained through the difference of interaction between the TEOS films and water in liquid or vapor form. The TEOS films obtained are hydrophobic and therefore can protect the grains from water vapor. Once immersed in water, the OEt radicals of the film are hydrolyzed following Equation 2. The kinetics of this hydrolysis depends on the "quantity" of water to which the film is exposed: when the films are exposed to water vapor, the hydrolysis is not complete and the films remain hydrophobic and resistant to exposition to water vapor. When the films are dipped in water, hydrolysis occurs and results in the formation of microchannels, which facilitate water adsorption and diffusion of water within the film.

$\mathrm{Si}(\mathrm{OEt})_{x}+\mathrm{H}_{2} \mathrm{O} \rightarrow \mathrm{Si}(\mathrm{OEt})_{x-1} \mathrm{OH}+\mathrm{EtOH}$

This hydrolysis has already been evidenced through the formation of $\mathrm{SiOH}$, which was shown by $\mathrm{FTIR}^{10}$. The presence of these microchannels with $\mathrm{SiOH}$ at their surface could explain the acceleration of germination since the diffusion of water to the grain surface, necessary to accelerate the germination process is enhanced by the larger specific area and affinity towards water of the grains surface.

In order to verify such hypothesis, quartz crystal measurements were carried out. A $4800 \AA$ thick TEOS film was deposited on a $4.096 \mathrm{MHz}$ quartz crystal (using $200 \mathrm{~W}$ and 200 mTorr TEOS plasma). The experimental setup is described elsewere ${ }^{24}$. The measurement was carried out using a $5 \mathrm{~mL} / \mathrm{min}$ nitrogen flow rate saturated with water vapor by passing it through liquid water. Before and after each exposure only nitrogen was flowed to the chamber test cell. Figure 4 shows the comparison of the frequency of the quartz crystal as a function of time for a TEOS film without any treatment (as deposited, Figure 4a) and after immersion in water for $3 \mathrm{~min}$ (Figure 4b) or $1 \mathrm{~h}$ (Figure 4c). It can be seen that a different behavior is obtained for all films. All films are shown to adsorb water but other interactions between water and the film are evidenced when the film was immersed in water.

For both the "as deposited" (Figure 4a) and immersed for $3 \mathrm{~min}$ (Figure $4 \mathrm{~b}$ ) films, when the water is admitted into the cell, a small and quick decrease of the frequency, which corresponds to an adsorption of water only on the surface of the film, is obtained. In the case of the "as deposited" film, the decrease of frequency quickly reaches a steady state but not in the case of the film immersed for 3 min. For the three minutes immersed film, simultaneously to the water adsorption, the nitrogen that was adsorbed previously by the film desorbs and the frequency starts to rise to a frequency higher than the base line of nitrogen, which is substituted by water at the film surface and is heavier than water. Therefore, the surface has been modified by the immersion since it is possible to observe a less steep variation immediately after the water admission, probably due to the formation of some microchannels on the surface. For the film immersed during $1 \mathrm{~h}$ (Figure 4c), after a small and abrupt variation, the frequency decreases slowly and continuously. This behavior indicates that adsorption and diffusion through the film is occurring. When the admission is closed (after $17 \mathrm{~min}$ ) the baseline does not return to the former value. Therefore a strong interaction between water and the film has occurred most likely due to hydrolysis and microchannel formation through the film.

This difference of interaction between the film and water in vapor and liquid phase can explain why the grains treated by plasma are resistant to humid environment and why their germination is accelerated. When the grains are continuously moistened during the germination experiments, the formation of channels within the films increases water uptake of the grains resulting in a faster germination. 

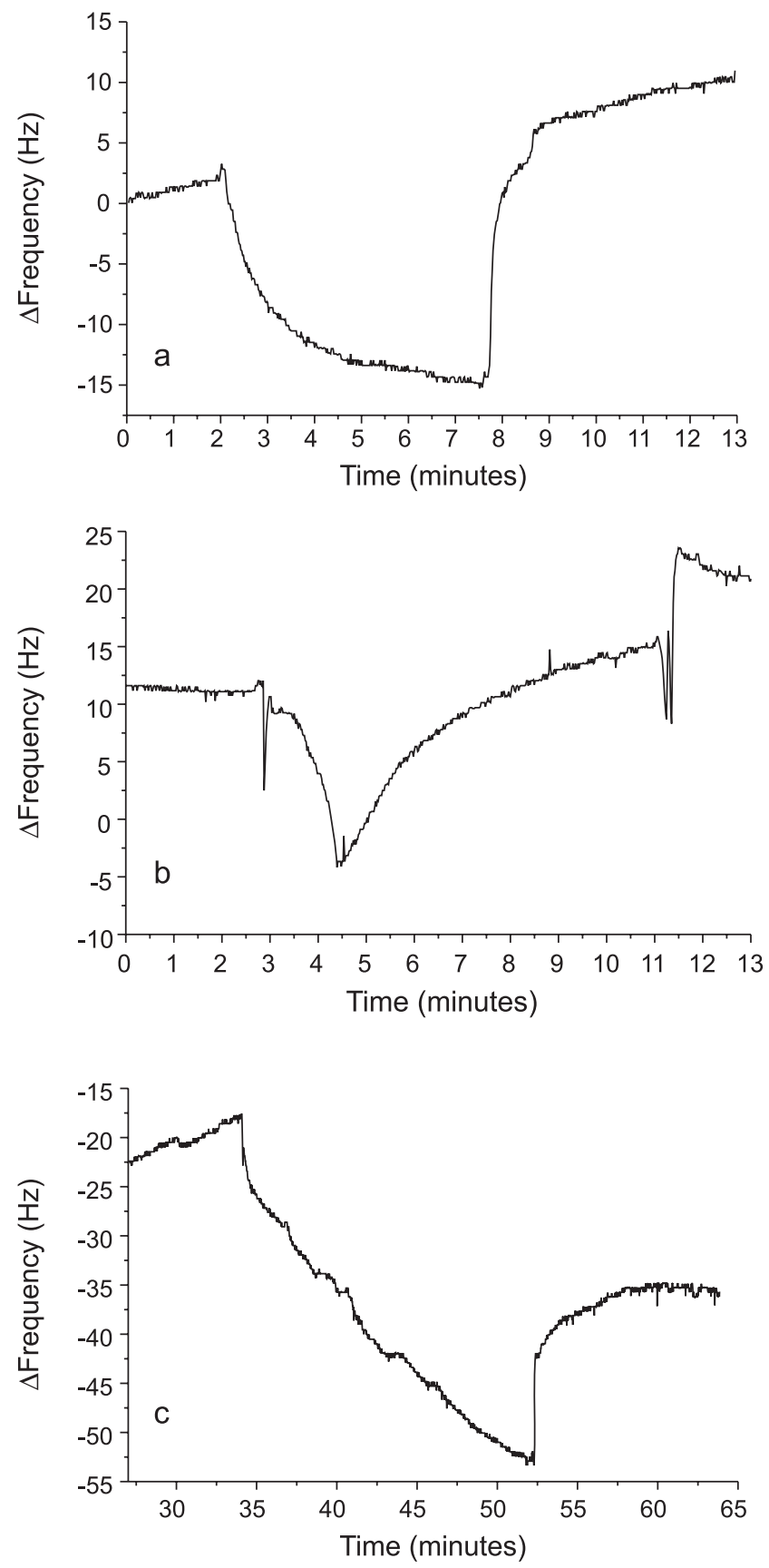

Figure 4. Comparison of frequency variation versus time for a TEOS film as deposited (a) and after immersion in water for $3 \mathrm{~min}(b)$ or $1 \mathrm{~h}(\mathrm{c})$

\section{CONCLUSIONS}

PECVD of TEOS or TEOS $+\mathrm{O}_{2}$ results in the production of hydrophobic films that are resistant to water vapor. Once dipped in water, these films suffer a hydrolysis resulting in a change of microstructure which turns them hydrophilic. These films can be used successfully to protect grains from biological degradation when exposed to vapor pressure and to enhance the germination of these grains if continuously moistened.

\section{ACKNOWLEDGEMENT}

FAPESP for financial support.

\section{REFERENCES}

1. Lan, J. K.; Wang, Y. L.; Chao, C. G.; Lo, K.; Cheng, Y. L.; J. Vac. Sci. Technol., B 2003, 21, 1224.

2. Yi, C.; Rhee, S. W.; J. Vac. Sci. Technol., A 2002, 20, 398.

3. Kim, M. T.; Thin Solid Films 2000, 360, 60.

4. Kim, J. Y.; Hwang, M. S.; Kim, Y. H.; Kim, H. J.; Lee, Y.; J. Appl. Phys. 2001, 90, 2469.

5. Shim, C.; Yang, J.; Jung, S.; Jung, D.; Thin Solid Films 2002, 415, 83.

6. Aumaille, K.; Vallee, C.; Granier, A.; Goullet, A.; Gaboriau, F.; Turban, G.; Thin Solid Films 2000, 359, 188.

7. Silva, M. L. P.; Cardoso, A. R.; Revista Brasileira de Aplicações de Vácuo 2002, 1-2, 22.

8. Hey, H. P. W.; Sluijk, B. G.; Hemmes, D. G.; Solid State Technol. 1990, $33,139$.

9. Iriyama, Y.; Ihara, T.; Kiboku, M.; Thin Solid Films. 1996, 287, 169.

10. Carvalho, R. A. M.; Silva, M. L. P.; Silva, A. N. R.; Tenth International Conference on Composites/nano engineering, New Orleans, Estados Unidos, 2003.

11. Carvalho, R. A. M., Dissertação de Mestrado, Escola Politécnica, Universidade de São Paulo, Brasil, 2004.

12. Carvalho, R. A. M.; Lima, R. R.; Nascimento Filho, A. P.; Silva, M. L. P.; Demarquette, N. R.; Chem. Sensors 2004, 20, supplement B, 654.

13. Hon, D.N.S.; Polymers News 1992, 17, 102.

14. Rowell, R. M. In Handbook on Wood and Cellulosic Materials; Hon, D.N.S.; Shiraishi, N., eds.; Marcel Dekker Inc.: New York, 1973, p. 703.

15. Volin, J. C.; Denes, F. S.; Young, R. A.; Park, S. M. T.; Crop Science 2000, 40, 1706.

16. Carvalho, A. T.; Carvalho, R. A. M.; Silva, M. L. P.; Demarquette, N. R.; Assis, O. B. G.; $4^{\text {th }}$ International Symposium on Natural Polymers and Composites, São Pedro, Brasil, 2002.

17. Magalhaes, W. L. E.; Souza, M. F.; Surf. Coat. Technol. 2002, 155, 11.

18. Collis-George, N.; Hector, J. B.; Aust. J. Soil Res. 1966, 4, 145.

19. Gonçalves, L. C. D.; da Silva, A. N. R.; Morimoto, N. I., Cortes, A.; Santos, J. C.; $17^{\text {th }}$ Symposium on Microelectronics Technologies and Devices, Porto Alegre, Brasil, 2002.

20. Tan, I. H.; Demarquette, N.R.; Silva, M. L. P.; Degasperi, F. T.; Dallacqua, R.; ISPC-14 Symposium Proceedings, Tchec. Republic, 1999.

21. Lima, R. R.; Carvalho, R. A. M.; Silva, M. L. P.; Demarquette, N. R.; $8^{\text {th }}$ SBMicro, São Paulo, Brasil, 2003.

22. Taylor, A. G.; Allen, P. S.; Bennett, M. A.; Bradford, K. J.; Burris, J. S.; Misra, M. K.; Seed Sci. Res. 1988, 8, 245.

23. Warren, J. E.; Bennett, M. A.; HortScience 1997, 32, 1220

24. Nascimento Fo , A. P.; Silva, M. L. P.; Galeazzo, E.; Demarquette, N. R.; Sens. Actuators, B 2003, 91, 370. 